\title{
Interactions Between Non-Allelic Loci and Their Effects on Categorized Meat Performance Traits in Ducks
}

-Author(s)

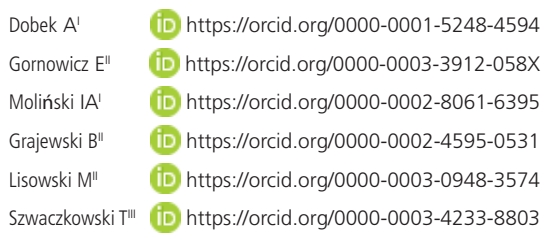

Poznan University of Life Sciences, Department of Mathematical and Statistical Methods, Wojska Polskiego st. 28, 60-637 Poznań, Poland.

Experimental Unit Station of National Institute of Animal Production Koluda Wielka, Waterfowl Genetic Resource Station Dworzyska, 62-035 Kórnik, Poland.

III Poznan University of Life Sciences, Department of Genetics and Animal Breeding, Wołyńska st. 33, 60-637 Poznań, Poland

\section{-Mail Address}

Corresponding author e-mail address Tomasz Szwaczkowski

Poznan University of Life Sciences, Department of Genetics and Animal Breeding, Wolynska st. 33, 60-637 Poznań, Poland.

Phone: +48-618487249

Email: tomasz.szwaczkowski@up.poznan. $\mathrm{p}$

\section{EKeywords}

Duck, categorized traits, entropy analysis, microsatellite markers.

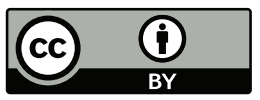

Submitted: $27 /$ June/2019 Approved: 19/March/2020

\section{ABSTRACT}

Traits associated with meat performance are characterized by a complex inheritance model, including the effects of non-allelic interactions. The aim of this study was to estimate the significance of non-allelic interactions between pairs of loci in each of two alternative groups based on four important performance traits of ducks: body weight (BW), carcass yield calculated as the ratio of carcass weight to body weight $(C Y)$, breast and leg muscle yield as a fraction of carcass weight (BL-CW), and skin weight and abdominal fat, again as a fraction of carcass weight (SF-CW). The experimental material was based on an F2 cross between two parental lines: A-55 (Polish Peking) and GL30 (French Peking). In total, 368 individuals were recorded. All of the birds (including parents and F1) were genotyped for 23 polymorphic microsatellite loci. Entropy was taken as a measure of interaction between pairs of loci, and the chi-square test was used to verify significance. In total, 253 pairs of loci were analyzed in both categories of each of the four traits. Statistically significant interactions were obtained for each trait. However, it was observed that some of the loci showed a greater tendency to have significant opposite interactions for alternative categories of the same trait. The results indicate the dependence of the recombination rate within pairs of loci on the level of each of the four traits.

\section{INTRODUCTION}

Some performance traits of poultry of importance to both consumers and breeders can be classified as binary (for instance, satisfactory and not satisfactory). By definition, identified single loci are also categorized according to their genotypes. There are a number of reports on association studies of additive genetic effects of molecular markers with continuous animal performance traits (see e.g. Andersson et al., 1994; Aulchenko et al., 2007). On the other hand, it is well known that the genetic backgrounds of some traits are complex, including additive and non-additive effects between alleles vs. loci. Classical estimation of non-additive genetic effects (based on mixed model methodology) requires a very large data set with favorable pedigree structure, family size, many highly polymorphic loci, etc.

Pekin duck is becoming an increasingly popular poultry species among breeders not only in Asian countries, but also in Europe. Over recent years, a considerable upward trend in duck meat production has been recorded in some European countries. Godfray et al. (2018) reported that meat accounts for more than 30\% of total food consumption around the world. The trend also corresponds with an increasingly diversified poultry meat market (Magdelaine et al., 2008). 
Dobek A, Gornowicz E, Moliński IA, Grajewski B, Lisowski M, Szwaczkowski T
Interactions Between Non-Allelic Loci and Their Effects on Categorized Meat Performance Traits in Ducks
Unfortunately, in contrast to chicken and livestock mammals, the duck (Anas platyrhynchos) genome is still insufficiently known. There are several papers on the detection of genome regions determining important performance traits (Huang et al., 2006, 2007a; Maak et al., 2003; Mucha et al., 2014; Dobek et al., 2017; Zhang et al., 2018). Huang et al. (2006) developed a genetic linkage map for the duck. In a later study (Huang et al., 2007b) they identified some loci affecting body weight and conformation traits as well as carcass and meat quality traits in Beijing ducks. Also Mucha et al. (2014) found one highly significant QTL for skin weight at the beginning of the linkage group CAU1, as well as two significant QTLs for fatness of leg muscle and leg muscle electrical conductivity 24 hours post-slaughter. Recently, estimation of genomic variation in Pekin duck populations has been carried out (Zhang et al., 2018; Zhu et al., 2019).

To our knowledge, there are no existing reports on inter- and intralocus interactions in duck populations. However, these interactions may be perceived as good indicators of linkages in animal groups classified according to the level of studied traits.

The present study is a continuation of earlier work by Mucha et al. (2014), Moliński et al. (2015) and Dobek et al. (2017) with the same experimental material, based on a crossbreeding experiment. Today, studies on interlocus interactions are possible due to the advantages of statistical tools, such as the theory of information. This approach, especially entropy analysis, has been applied for human (e.g. Andrew et al., 2006; Kang et al., 2008) and livestock populations (e.g. Dobek et al., 2012) to measure the uncertainty associated with the values of the traits. It is well known that productive traits are caused by multiple factors, namely locus main effects as well as locus-locus and locus-environment interaction. In this work we are most interested in the locus-locus interaction, being a form of epistasis. As entropy is commonly used to measure the uncertainty of random variables, we shall use an entropy-based test to establish the locus interactions. This approach has been applied in epidemiological studies by Kang et al. (2008). The so-called case-control design has been successfully employed in genetic association studies. To our knowledge there are no existing reports on the application of this methodology to livestock and poultry genetics.

The objective of this study was to examine the interactions between pairs of loci in two alternative groups of ducks defined according to trait levels.

\section{MATERIAL AND METHODS}

The experimental material was based on an F2 cross between two parental lines: A-55 (Polish Peking) and GL-30 (French Peking). In total, 390 individuals were recorded. More details on the crossbreeding experiment and housing and feeding management were given by Mucha et al. (2014). The experimental procedures were approved by the Local Ethics Committee for Animal Experiments in Poznań (Poland) by way of Resolution $60 / 2009$. In the $11^{\text {th }}$ week of life (before slaughtering), body weight was measured (using an AXIS B15S electronic balance with $\pm 5 \mathrm{~g}$ accuracy) on live birds after 12 hours without access to feed but with permanent access to water. Slaughter and post-slaughter processing were performed in the same standard technological conditions. Dissection was performed using the method described by Ziołecki \& Doruchowski (1989). Carcasses and their components were weighed with a RADWAG WPT 5C electronic balance with $\pm 0.2 \mathrm{~g}$ accuracy. Body weight (BW), carcass yield (CY) calculated as the ratio of carcass weight to body weight, breast and leg muscle yield as a fraction of carcass weight (BL-CW), and skin weight and abdominal fat, again as a fraction of carcass weight (SFCW) were recorded for each bird. A statistical description of the data is given in Table 1. The study included 23 loci, forming 253 pairs of loci. The primers for amplification of microsatellite sequences were chosen based on the literature (Huang et al., 2005). A detailed description of the molecular methods applied in the present study was given by Mucha et al. (2014). The microsatellite markers used are presented in Table 2.

Table 1 - Statistical characteristics of analyzed traits (means and standard deviations).

\begin{tabular}{lccc}
\hline Trait & Lower & Upper & Total \\
\hline BW $(\mathrm{g})$ & 2878.83 & 3354.81 & 3122.00 \\
& $(167.96)$ & $(165.42)$ & $(290.64)$ \\
\hline CY (\%) & 73.09 & 76.72 & 75.02 \\
& $(2.29)$ & $(2.56)$ & $(3.03)$ \\
\hline BL-CW (\%) & 23.18 & 25.95 & 24.47 \\
& $(1.09)$ & $(1.15)$ & $(1.78)$ \\
\hline SF-CW (\%) & 28.33 & 33.44 & 31.78 \\
& $(2.56)$ & $(2.07)$ & $(14.34)$ \\
\hline
\end{tabular}

BW- body weight, CY - carcass yield, BL-CW - breast and leg muscle yield as a fraction of carcass weight, SF-CW - skin weight and abdominal fat as a fraction of carcass weight.

For each recorded trait, the observations were divided into two sets, the average value being the boundary. The sets were denoted as lower $(L)$ and upper (U): BW-L, BW-U, CY-L, CY-U, BL-CW-L, BL-CW-U, SFCW-L, SF-CW-U. Thus, eight data sets were analyzed separately. The interaction of loci was examined for the whole set of ducks as well as for the eight sets of observations. In total there were 2024 variants of 
analysis. For each variant an incidence matrix was constructed based on the number of individuals with given genotypes.

Table 2 - Characteristics of analysed microsatellite loci.

\begin{tabular}{|c|c|c|}
\hline Locus & GenBank accession & Primer sequences $\left(5^{\prime}-3^{\prime}\right)$ \\
\hline CAUD093 & AY493338 & $\begin{array}{l}\text { AGAGCGGTGTGAGAGCAGAG } \\
\text { GATATCGCTCGCAATTTGG }\end{array}$ \\
\hline CAUD112 & AY587031 & $\begin{array}{l}\text { CAACTGACAGAGAGGCACG } \\
\text { GACTGTGTTTCCAATGCTCC }\end{array}$ \\
\hline CAUD086 & AY493331 & $\begin{array}{l}\text { AACACAGCTTCACCCCACAG } \\
\text { GCAGAGCGGTGTGAGAGCA }\end{array}$ \\
\hline CAUD039 & AY493284 & $\begin{array}{l}\text { GGGACATCTCTTGGAGCAAA } \\
\text { AGTGAAAGCTGCTGCTGGAT }\end{array}$ \\
\hline CAUD027 & AY493272 & $\begin{array}{l}\text { AGAAGGCAGGCAAATCAGAG } \\
\text { TCCACTCATAAAAACACCCACA }\end{array}$ \\
\hline CAUD114 & AY587033 & $\begin{array}{l}\text { GAAGCAAGGAAATCATCAGCC } \\
\text { GGATGTGGGGTGGTTATGAC }\end{array}$ \\
\hline CAUD066 & AY493311 & $\begin{array}{l}\text { ACCGCCTGGGGAATAATG } \\
\text { CGCTCTGTTGCTCTTGTAA }\end{array}$ \\
\hline $\mathrm{APH} 23$ & AJ515898 & $\begin{array}{l}\text { TCCTCTGCTCTAGTTGTGATGG } \\
\text { CCTCAGCAGTCTTCCTCAGTG }\end{array}$ \\
\hline CAUD018 & AY493263 & $\begin{array}{l}\text { TTAGACAAATGAGGAAATAGTA } \\
\text { GTCCAAACTAAATGCAGGC }\end{array}$ \\
\hline CAUD074 & AY493319 & $\begin{array}{l}\text { CAAGCCCTGGACCTATTCAG } \\
\text { GAGATGGGAAGGGAGAGAGG }\end{array}$ \\
\hline CAUD029 & AY493274 & $\begin{array}{l}\text { GACCTCAAGAATTTACCAC } \\
\text { ATTATTTTCTTCTGGCAGCA }\end{array}$ \\
\hline CAUD107 & AY587026 & $\begin{array}{l}\text { GCCATCTTAACCCCCTGAC } \\
\text { TTTACGCTTCCCTGTGCTTG }\end{array}$ \\
\hline SMO07 & AJ427847 & $\begin{array}{l}\text { TTTCACCCAGTTCACTTCAGCC } \\
\text { GATTCAAATTTGCCGCAGGATTA }\end{array}$ \\
\hline CAUD023 & AY493268 & $\begin{array}{l}\text { CACATTAACTACATTTCGGTCT } \\
\text { CAGCCAAAGAGTTCAACAGG }\end{array}$ \\
\hline CAUD095 & AY493340 & $\begin{array}{l}\text { CGCAGCGAGTTTCCAGAC } \\
\text { GTTCCCTTTCGCTCGTGTTA }\end{array}$ \\
\hline CAUD031 & AY493276 & $\begin{array}{l}\text { AGCATCTGGACTTTTTCTGGA } \\
\text { CACCCCAGGCTCTGAGATAA }\end{array}$ \\
\hline APH15 & AJ515890 & $\begin{array}{l}\text { TGAATATGCGTGGCTGAA } \\
\text { CAGTGAGGAATGTGTTTGAGTT }\end{array}$ \\
\hline CAUD127 & AY587046 & $\begin{array}{l}\text { CACTCATGGGACTACACTGT } \\
\text { CAGATGAAAATAAACTCCAG }\end{array}$ \\
\hline CAUD025 & AY493270 & $\begin{array}{l}\text { AGTTCATCCCGATTTGTAGC } \\
\text { AAATGCAGTGAGGTAAACCC }\end{array}$ \\
\hline CAUD131 & AY587050 & $\begin{array}{l}\text { CAGACTCCTGGAAACCTTCT } \\
\text { TGGGTTTTTGAACACAGATA }\end{array}$ \\
\hline CAUD020 & AY493265 & $\begin{array}{l}\text { TAGGGTCAATAGTAAGAAACA } \\
\text { TAACTGTGTGATAAGGGAGA }\end{array}$ \\
\hline SMO06 & AJ427846 & $\begin{array}{l}\text { GGGGTGGGAAAGAAGCAGTTTAG } \\
\text { TCCTGGGACTTTGAAAGTGGCTC }\end{array}$ \\
\hline CAUD103 & AY587022 & $\begin{array}{l}\text { CATACTGGCATCATTCTGT } \\
\text { CGTAATGAGTGGGGAAAGAC }\end{array}$ \\
\hline
\end{tabular}

To examine the interaction between loci in the context of a selected productive trait, the notion of entropy will be used. The Shannon entropy for a discrete random variable $X$ is a function:

$$
E(x)=-\sum_{i} p\left(x_{i}\right) \log p\left(x_{i}\right)
$$

where $p\left(x_{i}\right)$ denotes the probability of $X$ taking the value $x_{i}$. In the case of two loci, one with $r$ genotypes and the other with c genotypes, the entropy takes the form

$$
E_{o b s}=-\sum_{i=1}^{r} \sum_{j=1}^{c} p_{i j} \log p_{i j}
$$

where $p_{i j}$ is the probability of the presence of an animal with the $i$-th genotype for the first locus and the $j$-th genotype for the second. If there is no interaction between loci, the entropy is equal to

$$
E_{\text {ind }}=-\sum_{i=1}^{r} \sum_{j=1}^{c} p_{i .} p_{. j} \log p_{i .} p_{. j}
$$

where $p_{i .}=\sum_{j=1}^{c} p_{i j}$ and $p_{. j}=\sum_{i=1}^{r} p_{i j}$.

It is known (Wilks, 1962) that the statistic $2 n\left(E_{\text {ind }}-E_{\text {obs }}\right)$, with $n$ being the number of observations, follows a $\chi^{2}$ distribution with $(r-1)(c-1)$ degrees of freedom. The rejection of this hypothesis indicates interaction between a pair of loci.

Additionally, the Pearson correlations among four variables were estimated. These computations were performed with the use of Statistical software (version 13.1, StatSoft, Tulsa).

\section{RESULTS}

The statistically significant interactions between the pairs of loci within two alternative categories of four recorded traits are given in Figures $1 \mathrm{a}-4 \mathrm{~b}$. In total, 253 pairs of 23 loci were analyzed. Relatively small Pearson correlation coefficients between the studied traits were obtained (Table 3). However, some of them were statistically significant $(-0.124,-0.180$ and -0.131 for BW and CY, CY and BL-CW, and BL-CW and SF-CW respectively).

Table 3 - Pearson's correlation coefficients between studied traits.

\begin{tabular}{llll}
\hline & CY & BL-CW & SF-CW \\
\hline BW & $-0.124^{*}$ & -0.033 & 0.0168 \\
\hline$C Y$ & & $-0.180^{*}$ & 0.077 \\
\hline BL-CW & & $-0.131^{*}$ \\
\hline
\end{tabular}

$* / p<0.05$

\section{Body weight}

The results for both body weight classes are given in Figures $1 a-b$. In the class of heavier birds (BW-L) four loci (CAUD018, CAUD131, CAUD074, SMO07) did not display interactions, whereas in the second class (BW$\mathrm{U})$ only one locus (CAUD127) is non-interactive. Hence, 


\section{BW-U}

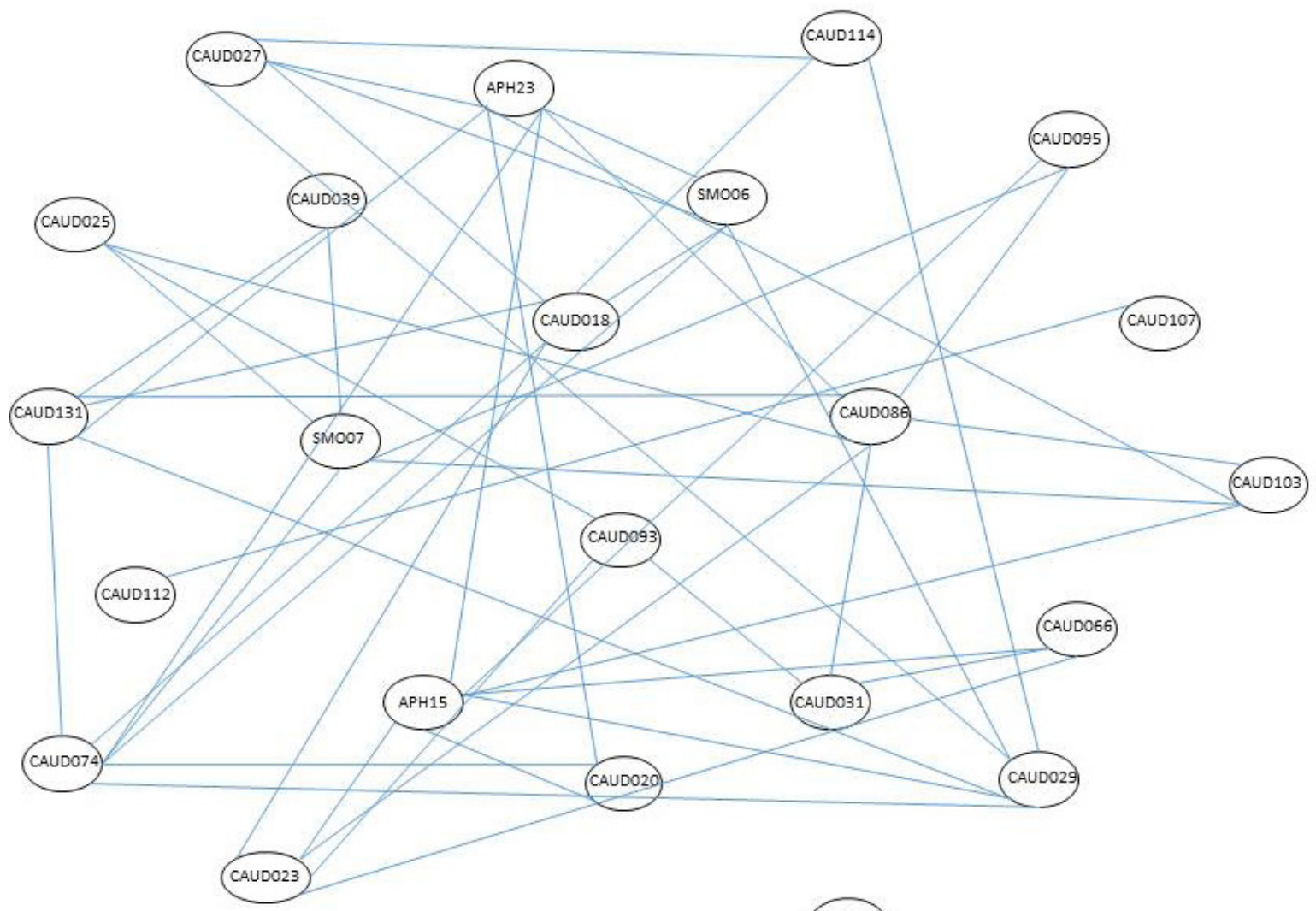

(CAUD127)

BW-L

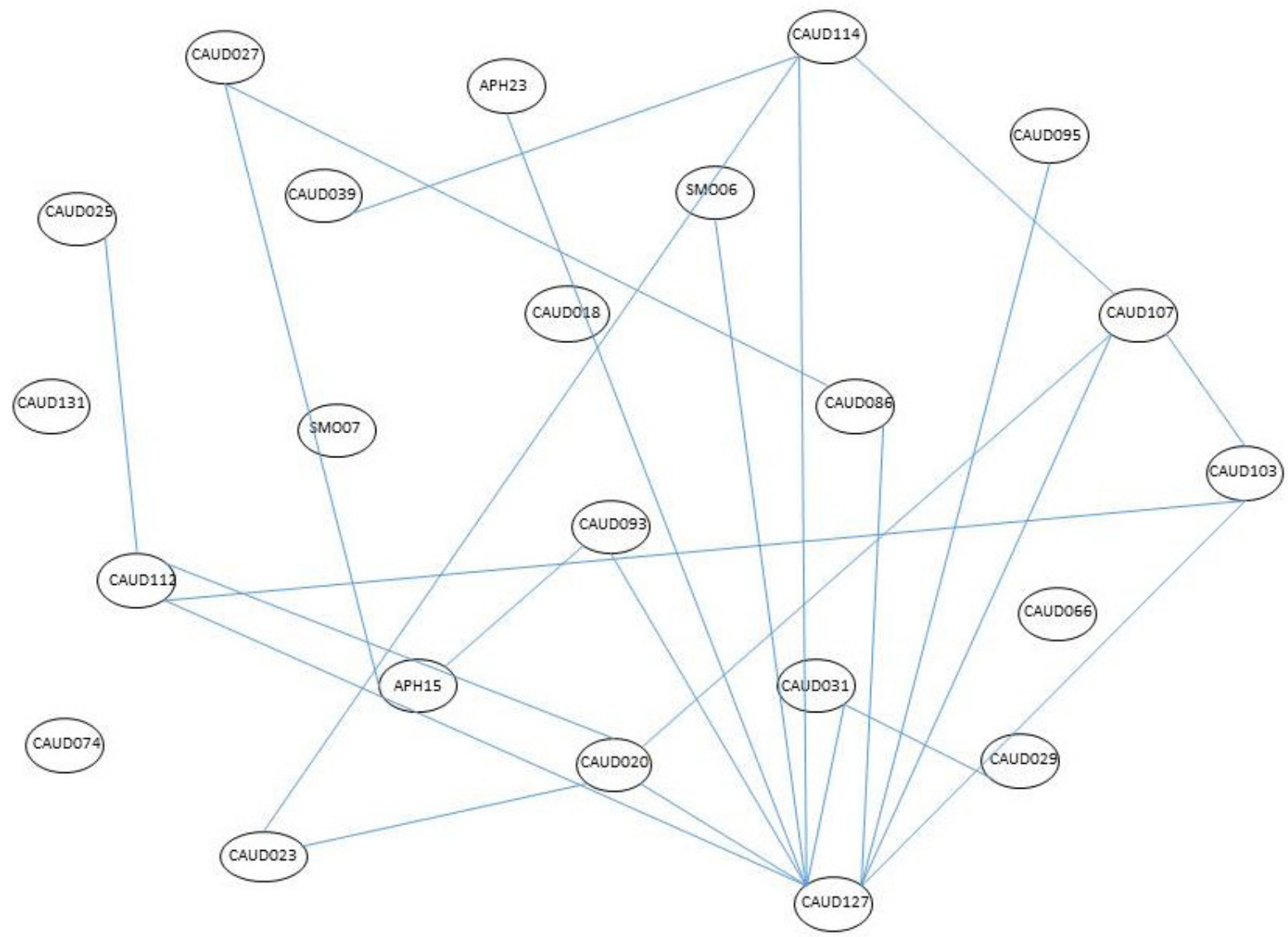

Figure 1a-b - Significiant interactions between non-allelic loci for alternative classes of body weight - upper (BW-U) and low (BW-L). 


\section{CY-U}

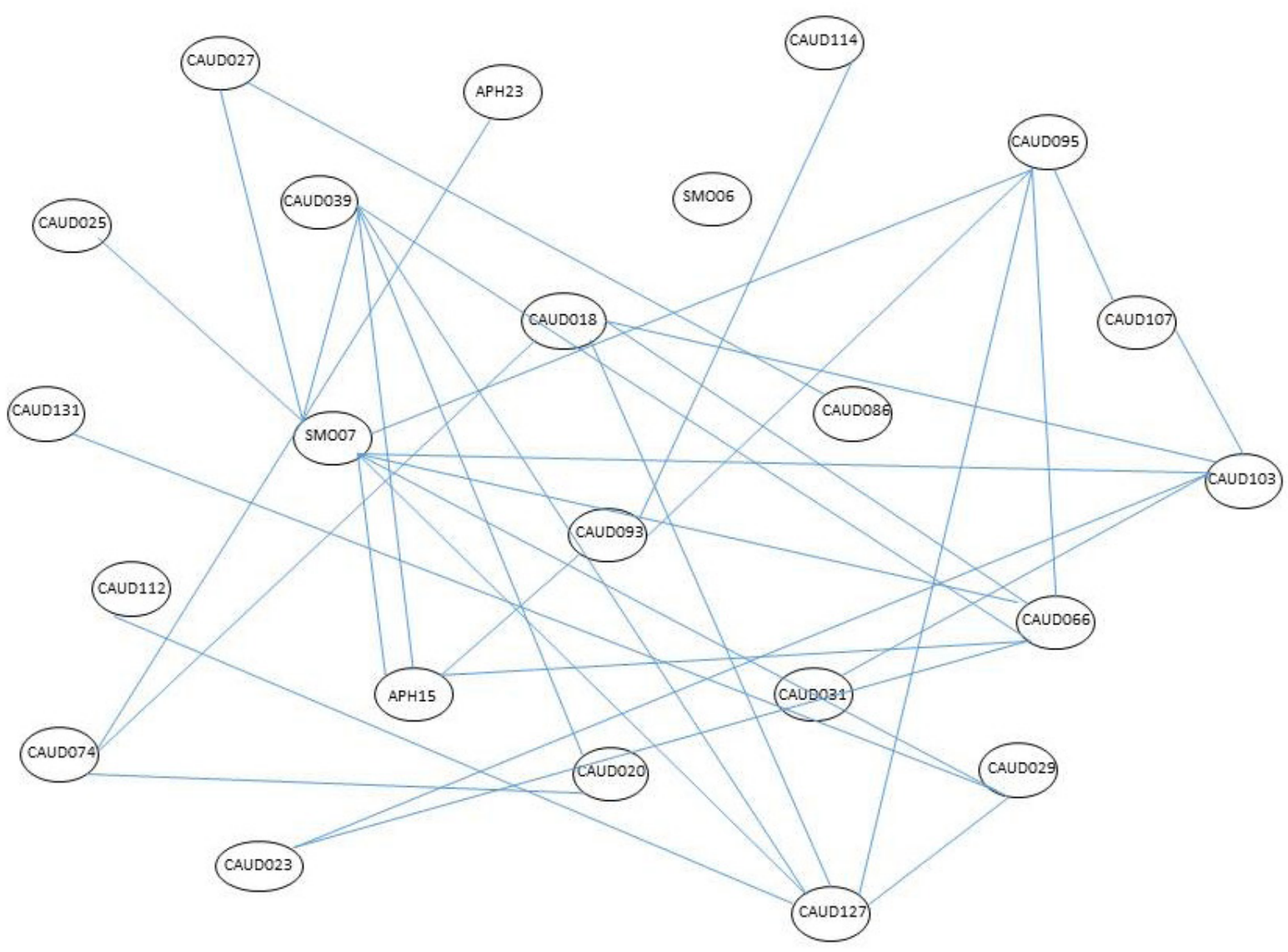

CY-L

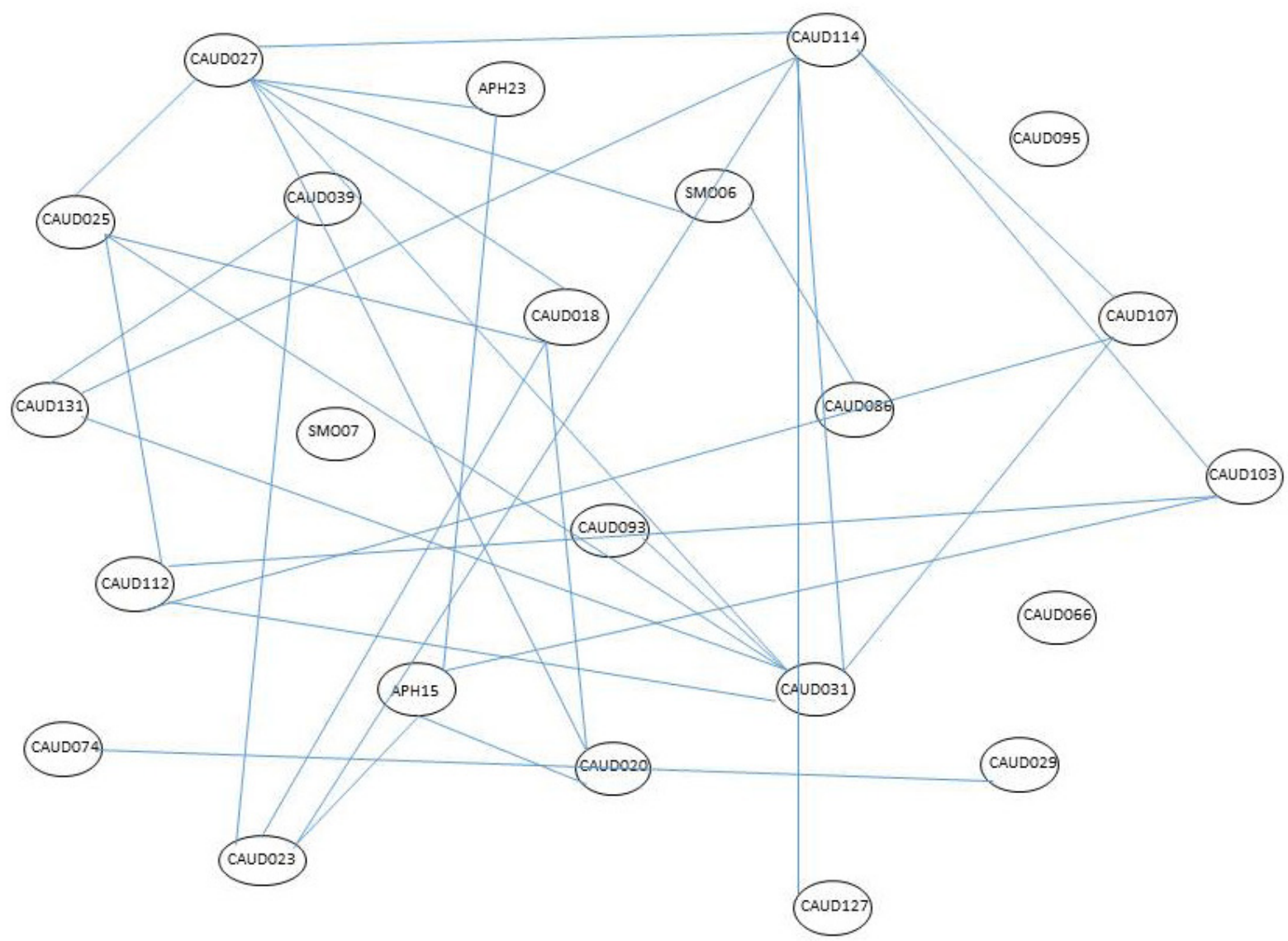

Figure 2a-b - Significiant interactions between non-allelic loci for alternative classes of carcass yield - upper (CY-U) and low (CY-L). 
Dobek A, Gornowicz E, Moliński IA, Grajewski B, Lisowski M, Szwaczkowski T
Interactions Between Non-Allelic Loci and Their Effects on Categorized Meat Performance Traits in Ducks interlocus interactions were detected for 19 and 22 loci in the two alternative data sets. However, the numbers of interactions with particular loci are very diverse in each of the two body weight classes. In the BW-L group, the most statistically significant interactions (11 interacting loci) were observed for the CAUD127 locus (with the following loci: APH23, CAUD020, CAUD031, CAUD086, CAUD093, CAUD095, CAUD103, CAUD107, CAUD112, CAUD114, SMO06). In this group, four loci (CAUD020, CAUD114, CAUD107, CAUD 112) displayed four significant interactions, and locus CAUD103 had three interactions. Generally, the distribution of interactions in the second class of ducks (heavier individuals) is quite different compared with the first class. The most interacting locus (with eight significant interactions) was APH23, whereas for three loci (CAUD131, CAUD029, APH15) six significant interactions were estimated. Each of the five loci (CAUD018, CAUD023, CAUD027, CAUD086, SM006) displayed five interactions. As already mentioned, there was a large variation between the groups for some loci. Extreme confirmation of this is provided by the locus that has no significant interactions for BW-L, but a large number of interactions for BW-U.

\section{Carcass yield}

The bi-locus interactions in both alternative classes of carcass yield are visualized in Figures $2 a-b$. The most important interacting loci in the CY-L group (each with seven interaction pairs) were CAUD027, CAUD031 and CAUD114. In the case of five loci, four interactions were statistically significant. In the case of the second group (CY-U) the largest interactive ability was demonstrated by the locus SMO07 (with nine loci: APH15, CAUD025, CAUD027, CAUD029, CAUD039, CAUD066, CAUD095, CAUD103 and CAUD127), followed by two loci (CAUD066, CAUD127) with six interactions. It should be noted that three loci (CAUD066, CAUD095 and SMO07) were interacting for CY-U, although in the case of CY-L they produced no statistically significant interactions. Antagonistic bilocus interactions were detected for both categories of carcass yield, especially for the markers SMO07, CAUD127, CAUD031 and CAUD066.

\section{Breast and leg muscle yield as a fraction of carcass weight}

As presented in Figures $3 a-b$, there were three non-interacting loci in each of the alternative groups (APH23, CAUD039 and CAUD093 for BW-CW-L, and SM006, CAUD066 and CAUD103 for BL-CW-U). However, the remaining markers displayed different degrees of interaction between loci (from 1 to 6). For instance, for CAUD031, seven bi-locus interactions were registered in the $B L-C W-L$ group, but only one in the alternative group (BL-CW-U). The opposite position was obtained for CAUD031, with interaction with six loci (CAUD095, CAUD107, CAUD074, CAUD127, CAUD086, CAUD093) in the BL-CW-U group, whereas the same locus in the alternative group (BL-CW-L) displayed interaction with one locus only. Considerable disproportion in the two categories was observed for CAUD029. In the case of BL-CW-L, this locus displayed interaction with seven microsatellite markers (CAUD027, CAUD114, SMO06, CAUD074, CAUD066, CAUD086, CAUD018), but in the alternative category (BL-CW-U) only one interaction (with CAUD112) was registered.

\section{Skin weight and abdominal fat as a fraction of carcass weight}

Generally, the number of interactive loci varied between the two categories based on this trait. The number of interactions for SF-CW-L was considerably smaller than for SF-CW-U. In the case of SF-CW-L (Figure 4a-b), seven loci (CAUD020, CAUD066, CAUD086, CAUD093, CAUD095, CAUD103, SMO06) did not interact, and for six other loci (APH23, CAUD025, CAUD029, CAUD031, CAUD074, CAUD131) only single interactions were detected. The largest numbers of interactions (in this category) were obtained for CAUD112 (six) and for APH15 (five bilocus interactions).

As already mentioned, in the case of the SF-CW-U data, the density of interactions was considerably larger than in the case of SF-CW-L. Here only one non-interacting locus (CAUD025) was detected. For two loci, CAUD029 and CAUD103, the numbers of significant interactions were eleven (APH15, CAUD066, CAUD074, CAUD086, CAUD093, CAUD095, CAUD103, CAUD114, CAUD131, SMO06, SMO07) and ten (APH15, APH23, CAUD018, CAUD023, CAUD029, CAUD031, CAUD074, CAUD107, CAUD112, SMO07) respectively.

\section{DISCUSSION}

Over recent decades, population scale sequencing projects have made large progress in documenting genetic structure in a number of species, including ducks. Also, current advances in molecular genetics and genomics have generated new opportunities for genetic improvement programs due to the association of chromosomal regions with productive traits. However, the genetic backgrounds of numerous traits 
Dobek A, Gornowicz E, Moliński IA,

Grajewski B, Lisowski M, Szwaczkowski T
Interactions Between Non-Allelic Loci and Their Effects on Categorized Meat Performance Traits in Ducks

\section{BL-CW-U}

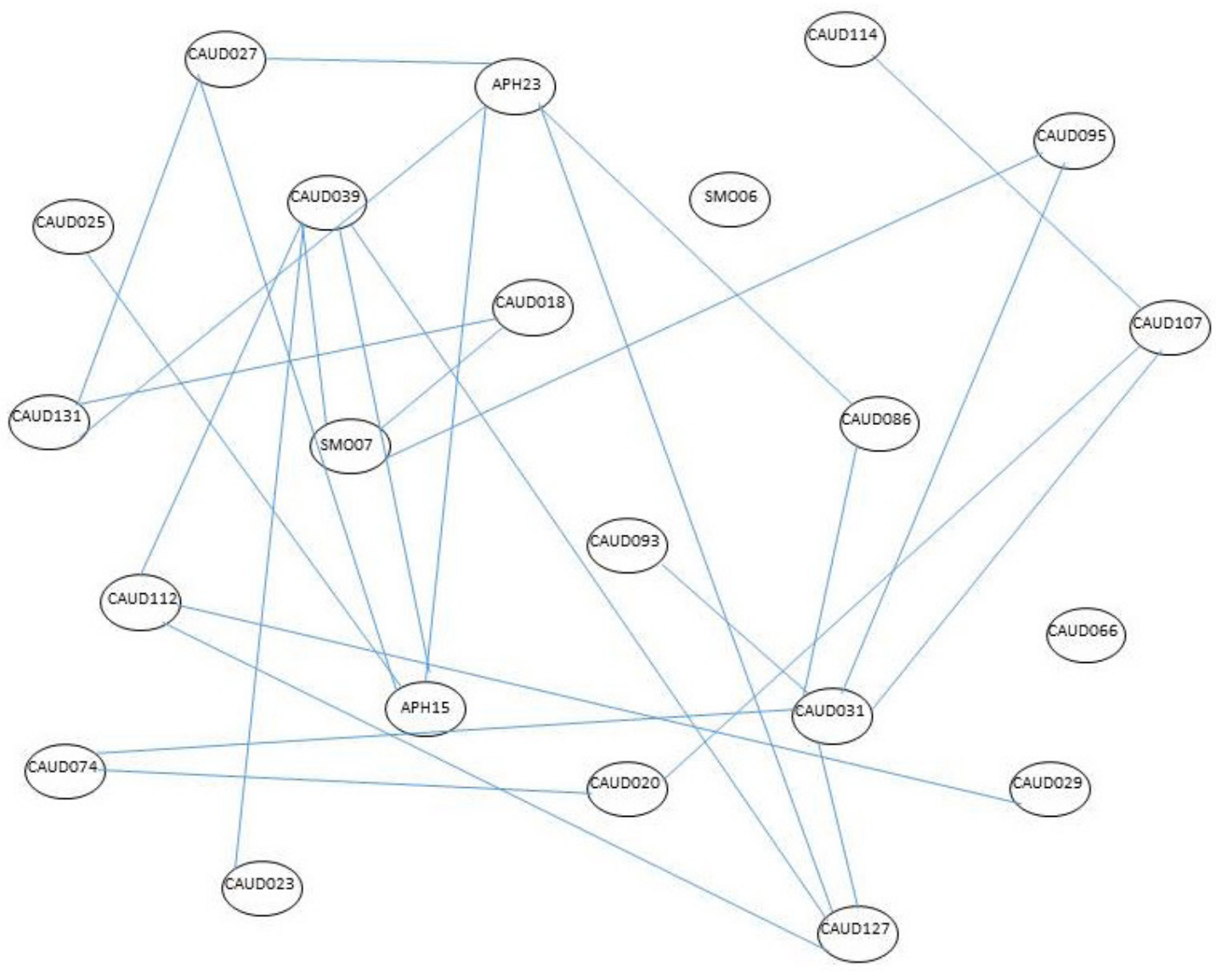

BL-CW-L

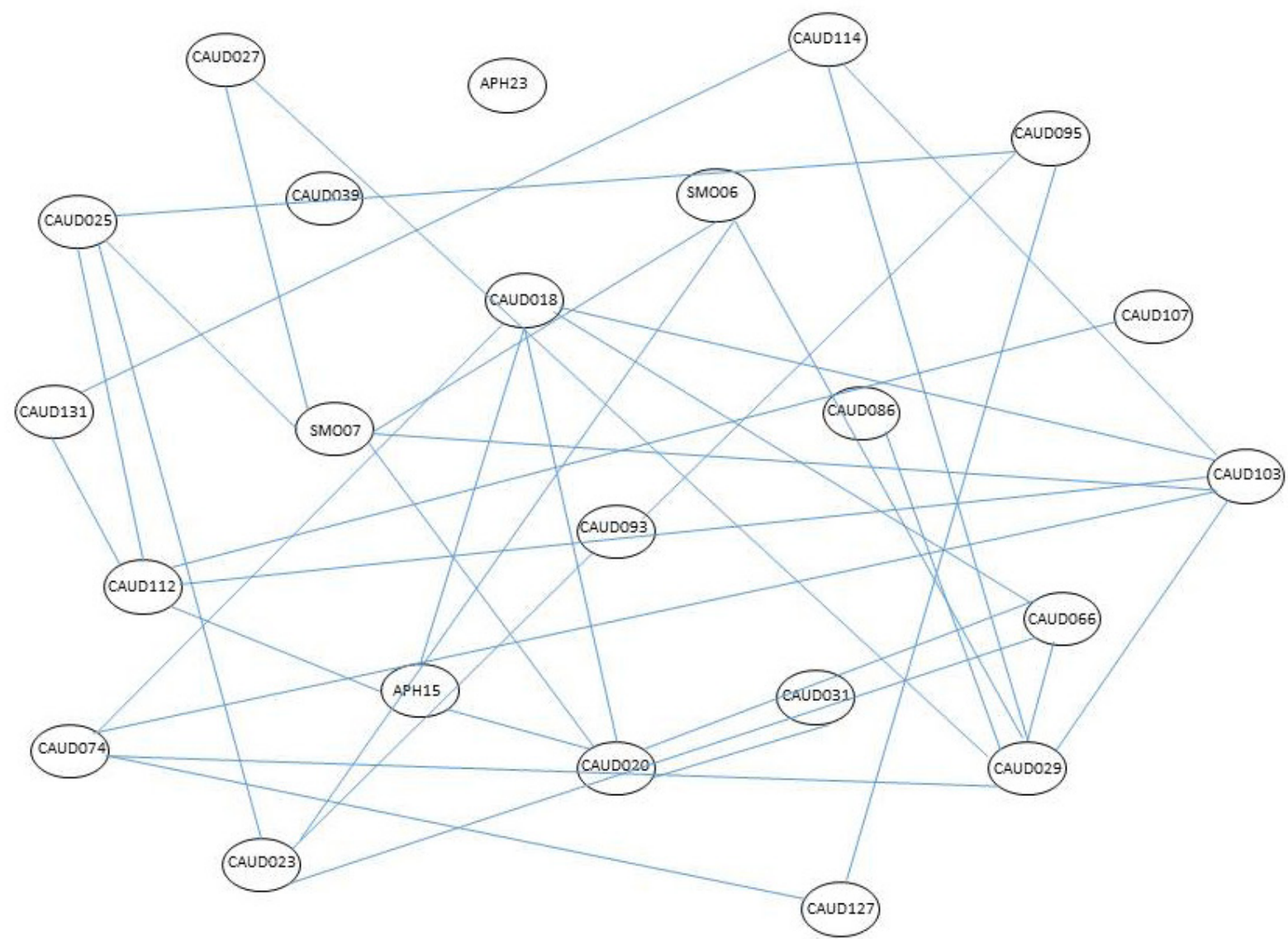

Figure 3a-b - Significiant interactions between non-allelic loci for alternative classes of breast and leg muscle as a fraction of carcass weight- upper (BL-CW-U) and low (BL-CW-L). 


\section{SF-CW-U}

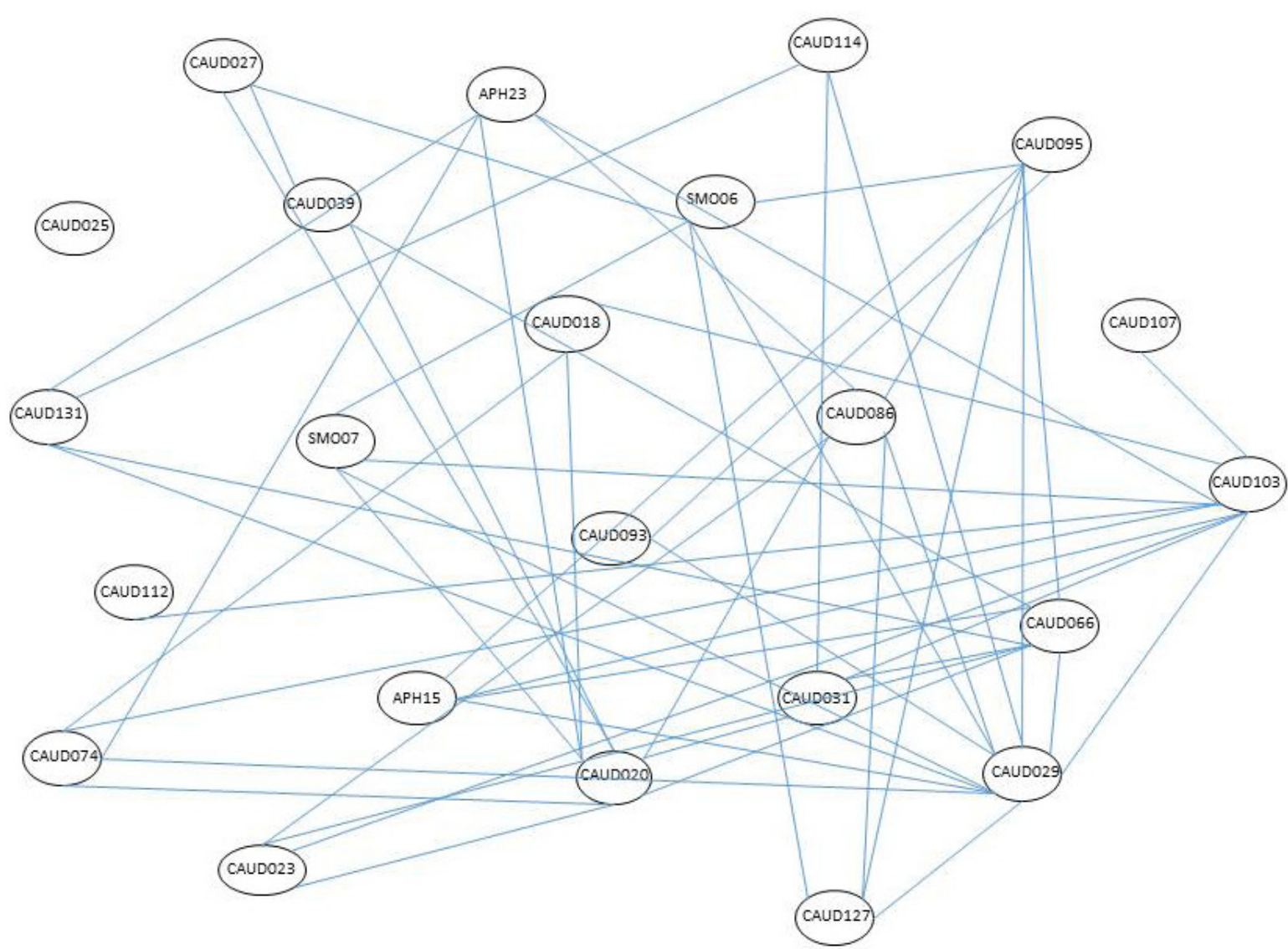

\section{SF-CW-L}

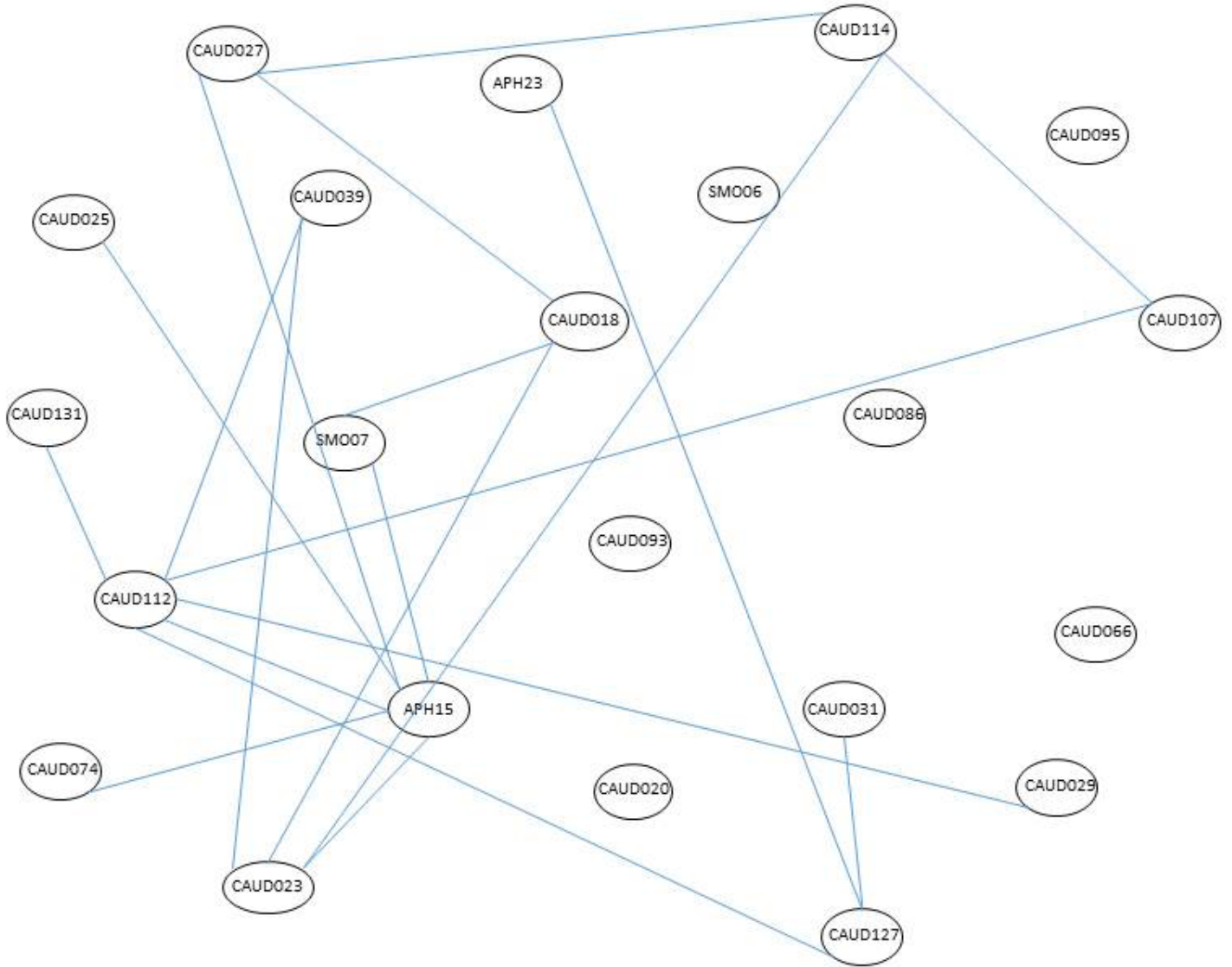

CAUD103

Figure 4a-b - Significant interactions between non-allelic loci for alternative classes of skin weight and abdominal fat as a fraction of carcass weight - upper (SF-CW-U) and low (SF-CW-L). 
Dobek A, Gornowicz E, Moliński IA, Grajewski B, Lisowski M, Szwaczkowski T

\section{Interactions Between Non-Allelic Loci and Their Effects on Categorized Meat Performance Traits in Ducks}

are very complex, including not only additive effects of loci, but also intra- and interlocus interactions. Kang et al. (2008) reported that identifying gene interactions using molecular tools is time-consuming and expensive in comparison with statistical methods, which may be perceived as an efficient alternative approach for elucidating the interaction mechanisms.

From a methodological point of view, due to the relatively large genetic and phenotypic variabilities, a crossbreed population appears to be suitable for the estimation of interlocus interaction. This is the case with the data studied in the present paper. Let us recall that the recorded and genotyped individuals originated from generation F2 of a crossbreeding experiment. On the other hand, as reported by Mucha et al. (2014), the polymorphism and, in consequence, heterozygosity of the genotyped loci are different. The polymorphism information content (PIC) of the studied microsatellite loci ranged from 0.29 (APH15) to 0.70 (CAUD131). Coefficients of observed and expected heterozygosity as well as polymorphism information content for this population (estimated by Mucha et al., 2014) are presented in Table 4. Baratti et al. (2015) observed a gametic disequilibrium for the APH15 and APH10 microsatellite loci in a mallard population in Italy.

Table 4 - Estimated parameters of expected $\left(H_{E} x p\right)$ and observed ( $\mathrm{H}_{0} \mathrm{bs}$ ) heterozygosity as well as polymorphism information content (PIC) of the studied loci (Mucha et al., 2014).

\begin{tabular}{|c|c|c|c|}
\hline Locus & HObs & HExp & PIC \\
\hline CAUD029 & 0.48 & 0.46 & 0.35 \\
\hline CAUD086 & 0.19 & 0.67 & 0.59 \\
\hline CAUD107 & 0.50 & 0.66 & 0.58 \\
\hline CAUD114 & 0.57 & 0.47 & 0.41 \\
\hline CAUD066 & 0.68 & 0.70 & 0.64 \\
\hline APH23 & 0.46 & 0.43 & 0.33 \\
\hline CAUD027 & 0.72 & 0.61 & 0.54 \\
\hline CAUD112 & 0.36 & 0.40 & 0.37 \\
\hline CAUD074 & 0.67 & 0.61 & 0.53 \\
\hline CAUD093 & 0.74 & 0.71 & 0.66 \\
\hline CAUD039 & 0.79 & 0.68 & 0.61 \\
\hline CAUD018 & 0.15 & 0.46 & 0.36 \\
\hline CAUD023 & 0.45 & 0.50 & 0.47 \\
\hline CAUD095 & 0.32 & 0.52 & 0.48 \\
\hline SMO07 & 0.37 & 0.34 & 0.32 \\
\hline CAUD031 & 0.75 & 0.67 & 0.60 \\
\hline APH15 & 0.35 & 0.35 & 0.29 \\
\hline CAUD127 & 0.34 & 0.35 & 0.31 \\
\hline CAUD103 & 0.32 & 0.34 & 0.30 \\
\hline CAUD025 & 0.53 & 0.47 & 0.36 \\
\hline CAUD131 & 0.79 & 0.74 & 0.70 \\
\hline CAUD020 & 0.28 & 0.26 & 0.22 \\
\hline SMO06 & 0.66 & 0.60 & 0.53 \\
\hline
\end{tabular}

In the present study, the number of statistically significant interactions varies between alternative trait classes. The largest number (12) of interactions in one subclass (SF-CW-U) was recorded for locus CAUD029, characterized by relatively low polymorphism $(P I C=0.35)$. Mucha et al. (2014), in a study on the same population, indicated locus CAUD029 as the flanking marker for fatness of leg muscle by sensory evaluation. According to those authors, CAUD029 explained $3.2 \%$ of the phenotypic variance of this trait. This may emphasize even more the role of the locus. Incidentally, the marker CAUD029 was indicated as being associated with the uniformity of basic performance traits in the analyzed population (Dobek et al., 2017). It should be noted that some other studied loci have also been indicated as important. Huang et al. (2007b) reported the microsatellite loci CAUD117, CAUD126 as flanking markers for body weight of Beijing ducks. In the analysis of breast muscle weight, one peak was obtained at $394 \mathrm{cM}$ (flanking markers: CAUD103 and (AUD025). This region was not in the neighborhood of the QTL reported by Huang et al. (2007a). In an earlier study (Moliński et al., 2015) performed on the same population, some of the most antagonistic interacting loci (CAUD086, 2CAUD093 and CAUD018) had discriminative properties. Also in the SF-CW-U subclass, ten significant interactions were observed for CAUD103. As with the previous locus, the polymorphism of this marker was small (PIC=0.30). In an earlier study (Mucha et al., 2014) CAUD103 was detected as a flanking marker for breast muscle weight.

The results obtained suggest that gametic equilibrium can be determined by the level of certain traits. It is well recognized that locus-locus interactions, also known as epistasis, may be one of the potential mechanisms implicating some traits. Definition of the phenomenon is not always clear. Epistasis is usually considered for a given trait (Ruiz-Larranaga et al., 2017). However, some authors (e.g. Kang et al., 2008) suggest the approach adopted in the present study, whereby gene-gene interactions are estimated for classes of traits.

The results of the present study call into question the random process of interactions between the studied loci. This is evidenced by the different numbers of interactions within alternative classes of all four recorded traits. As already noted, the numbers of interacting loci are relatively large. However, they were considerably differentiated across two classes of a single trait. On the other hand, in the case of some microsatellite markers, the numbers of most 
Dobek A, Gornowicz E, Moliński IA, Grajewski B, Lisowski M, Szwaczkowski T
Interactions Between Non-Allelic Loci and Their Effects on Categorized Meat Performance Traits in Ducks interacting loci are usually similar for alternative classes of different traits. This is mainly a consequence of correlations between the traits studied.

It is well known that the effectiveness of statistical inference is determined by the size of the subclasses. Therefore, in the case of highly polymorphic loci with a small number of subclasses, some interactions may not have been detected. Although there is not necessarily a direct relation between statistical and biological interactions, genetic interaction analyses can provide relevant information regarding the biological mechanism which might underlie the performance traits recorded (Kang et al., 2008).

To our knowledge, this is the first application of such an approach in poultry. As noted by Kang et al. (2008), the methodology has several advantages, such as the fact that the interactions among multiple loci can be characterized by the entropy of a locus system, and the possibility of evaluating associations of multiple loci with a binary expression of recorded traits. Let us recall that the categorization of performance traits is also very useful from a practical point of view.

It should be recalled that microsatellite loci are genetic markers (of the second class) not localized at any coding genome regions. Hence, only indirect associations (without physiological pathways) of these loci with performance traits can be considered. However, it is well known that they are widely applied to evaluate the genetic structure of a population (including its variation among populations and over time) and, in consequence, to study relationships with characteristics. However, apart from the above considerations, the results obtained in this work clearly indicate the rearrangements of microsatellite loci (alleles) within subgroups of birds. This may have larger implications for other genome regions, including those where coding areas (genes) are located.

In conclusion, the studies conducted provide some arguments for a complex inheritance model for the most important performance traits in ducks. This was confirmed by the number of opposite interactions between pairs of loci in each of two alternative groups of individual ducks classified according to the level of analyzed traits. The results suggest some non-random biological backgrounds of gametic disequilibrium.

\section{ACKNOWLEDGEMENTS}

The research project was supported by the Polish Ministry of Science and Higher Education, grant no. N N311 239838. We gratefully acknowledge the helpful comments of the anonymous reviewers who contributed to the improvement of this manuscript.

\section{DECLARATION OF INTEREST}

There is no conflict of interest with other works.

\section{REFERENCES}

Andrew AS, Nelson HH, Kelsey, KT, Moore, JH, Meng, AC, et al. Concordance of multiple analytical approaches demonstrates a complex relationship between DNA repair gene SNPs, smoking and bladder cancer susceptibility. Carcinogenesi 2006;27:1030-1037.

Andersson L, Haley CS, Ellegren H, Knott SA, Johansson M, Anderson K, et al. Genetic mapping of quantitative trait loci for growth and fatness in pigs. Science 1994;263:1771-1774.

Aulchenko YS, de Koning DJ, Haley C. Genome wide rapid association using mixed model and regression: a fast and simple method for genome wide pedigree-based quantitative trait loci association analysis. Genetics 2007;177:577-585.

Baratti M, Baccetti N, Cordaro M, Mori A, Dessi-Fulgheri F. Investigating the puzzling genetic structure of mallard populations (Anas platyrhynchos L.) in Italy. European Journal of Wildlife Research 2015;61:81-89.

Dobek A, Borowska A, Moliński K, Szwaczkowski T. Entropy analysis of performance test results of warmblood stallions. Journal of Animal and Feed Sciences 2012;21:77-88.

Dobek A, Gornowicz E, Moliński K, Grajewski B, Lisowski M, Szwaczkowski T. Successful identification of duck genome region determining desirable uniformity of meat performance traits. Brazilian Journal of Poultry Science 2017;19:437-444.

Godfray HCJ, Aveyard P, Garnett T, Hall JW, Key TJ, Lorimer J, et al. Meat consumption, health, and the environment. Science 2018;(6399):5324.

Huang Y, Tu J, Cheng X, Tang B, Hu X, Liu Z, et al. Characterization of 35 novel microsatellite DNA markers from the duck (Anas platyrhynchos) genome and cross-amplification in other birds. Genetics Selection Evolution 2005;37:455-472.

Huang Y, Zhao Y, Haley C, Hu S, Hao J, Wu C, et al. A genetic and cytogenetic map for the duck (Anas platyrhynchos). Genetics 2006;173:287-296.

Huang Y, Haley CS, Wu F, Hu S, Hao J, Wu C, et al. Genetic mapping of quantitative trait loci affecting carcass and meat quality traits in Beijing ducks (Anas platyrhynchos). Animal Genetics 2007a;38:114-119.

Huang Y, Haley CS, Hu S, Hao J, Wu C, Li N. Detection of quantitative trait loci for body weight and conformation traits in Beijing ducks. Animal Genetics 2007b;38:525-526.

Kang G, Yue W, Zhang J, Cui Y, Zuo Y, Zhang D. An Entropy-based approach for testing genetic epistasis underlying complex diseases. Journal of Theoretical Biology 2008;250:362-374.

Maak S, Wimmers K, Weigend S, Neumann K. Isolation and characterization of 18 microsatellites in the Peking duck (Anas platyrhynchos) and their application in other waterfowl species. Molecular Ecology Notes 2003;3:224-227.

Magdelaine P, Spiess MP, Valceschini E. Poultry meat consumption trends in Europe. World's Poultry Science Journal 2008;64:53-64.

Moliński K, Szwaczkowski T, Gornowicz E, Lisowski M, Grajewski B, Dobek A. New approach for the detection of loci determining duck meat quality. European Poultry Science 2015;79:1-10. 
Mucha S, Grajewski B, Gornowicz E, Lisowski M, Radziszewska J, Szwaczkowski T. Mapping quantitative trait loci affecting some carcass and meat traits in duck (Anas platyrhynchos). Journal of Applied Genetics 2014;55:497-503.

Ruiz-Larranaga O, Vázquez P, Iriondo M, Manzano C, Aguirre M, Joseba $M$, et al. Evidence for gene-gene epistatic interactions between susceptibility genes for Mycobacterium avium subsp. paratuberculosis infection in cattle. Livestock Science 2017;195:63-66.

Wilks SS. Mathematical statistics. New York: Wiley; 1962.
Zhang Z, Jia Y, Chen Y, Wang L, Lv X, Yang F, et al. Genomic variation in Pekin duck populations developed in three different countries as revealed by whole-genome data. Animal Genetics 2018;49:132-136.

Zhu F, Cheng S-R, Yang Y-Z, Hao J-P, Yang F-X, Hou Z-C. Genome-wide association study of growth and feeding traits in pekin ducks. Frontiers in Genetics 2019;702.

Ziołecki J, Doruchowski W. Method of slaughter value evaluation in poultry. COBRD Poznań 1989:1-32. (in Polish) 
